\title{
Cartografias em Análise do Discurso: rearticulando as NOÇÕES DE GÊNERO E CENOGRAFIA
}

\author{
(Cartographies in Discourse Analysis: revisiting the \\ articulation of genre and scenography)
}

\author{
Décio Rocha (Uerj / CNPq)
}

\begin{abstract}
Resumo: Este artigo centra-se nas noções de gênero do discurso e cenografia (Maingueneau, 1989). Após o exame do modo como o autor entende a articulação dos dois conceitos, em especial no que concerne à existência de gêneros desprovidos de cenografia, propõe-se que a cenografia está sempre presente, variando apenas seu grau de atualização. A análise de um anúncio de emprego e de uma receita médica possibilitará avaliar a pertinência de um ponto de vista segundo o qual o embate entre gêneros e cenografias pode ser traduzido pelo encontro de forças mais ou menos estabilizadas no plano dos discursos.

Palavras-chave: gênero do discurso; cenografia; anúncios classificados de emprego; receita médica.
\end{abstract}

Abstract: Thispaper discusses the notions of genre and scenography (Maingueneau, 1989). According to the author's point of view, there are genres which would not be invested with a scenography. Instead, we argue that scenography is always present. What is variable is its degree of actualization. By means of the analysis of a sample composed of texts of two genres - classified job advertisements and medical prescriptions - we shall evaluate the relevance of a point of view according to which the clash between genres and scenographies can be translated by the encounter of forces more or less stabilized.

Key-words: genre; scenography; classified job advertisements; medical prescription.

\section{1. À GUISA DE INTRODUÇão}

Este artigo tem um duplo objetivo: (i) com base nas noções de gênero do discurso e de cenografia (MAINGUENEAU, 2001), discutir a relação que se verifica entre cena genérica e investimento em uma dada cenografia, tomando como córpus texto extraído da mídia; (ii) propor modos alternativos de articulação entre esses dois planos. 
Inicialmente, explicito o conceito de discurso que fundamenta minha abordagem teórica. Tal definição é um passo necessário, uma vez que se trata de termo bastante polissêmico, objeto de abordagens teóricas muito diversificadas. Nesse sentido, tomando por base a reflexão de D. Maingueneau, entenderei por discurso uma realidade de dupla face: "uma que diz respeito ao social e a outra, à linguagem” (MAINGUENEAU, 1989, p. 55). Em outras palavras, como prática discursiva, o conceito de discurso nos reenvia ao ponto de encontro de uma formação discursiva e de uma comunidade discursiva: ao se produzirem textos, constitui-se necessariamente o grupo que se responsabiliza pela gestão desses textos; inversamente, toda produção de um grupo que se define por sua atividade enunciativa implicará a produção material de textos. Por essa razão, Maingueneau sustentará o conceito de prática discursiva para se referir a essa reversibilidade essencial entre as duas faces, social e textual, do discurso.

\section{BREVE RETROSPECTIVA: GÊNERO DO DISCURSO E CENOGRAFIA}

Maingueneau faz referência aos gêneros do discurso como sendo "dispositivos de comunicação sócio-historicamente definidos" (MAINGUENEAU, 1998, p. 73) e bastante diversificados, incluindo desde os de maior estabilidade (por exemplo, a prece, a receita de cozinha) aos mais fugazes (a publicidade, o telejornal, etc.). Ao caracterizar os gêneros, o autor oferece alguns dos itens que participarão de sua definição: (i) o status dos coenunciadores; (ii) o tempo e o espaço de enunciação; (iii) o suporte e os modos de circulação; (iv) os temas presentes, o modo de organização e o modo de coesão dos textos, etc.

São bastante complexas as relações que se estabelecem entre os gêneros do discurso e as diversas formações discursivas que deles se apropriam (e, de certa forma, os recriam, autorrecriando-se também): o gênero "aula" não será o mesmo, se dirigido a alunos universitários ou a alunos da escola fundamental; o gênero "sermão" não permanecerá o mesmo se for proferido por um religioso mais progressista ou mais tradicional; o gênero "publicidade" apresentará uma vasta gama de possibilidades em função do público a que se destina (público jovem ou não, pertencente a uma ou outra classe social, etc.), em função do produto anunciado (não se anuncia da mesma forma um carburante e um produto de beleza) ou do suporte (há variações sensíveis na composição das publicidades veiculadas na televisão, em 
revistas femininas ou em outdoors, por exemplo). De qualquer modo, seja qual for a configuração do gênero com o qual lidamos, uma coisa parece certa: ele sempre funciona como fator decisivo para a interpretação de um enunciado.

Em Análise de textos de comunicaşão, Maingueneau ainda avança no modo pelo qual compreende a noção de gêneros do discurso, articulando-a a outras noções que ajudarão a delimitá-la. Com efeito, o autor postula que os enunciados sejam compreendidos a partir da articulação de diferentes cenas, a saber, uma cena englobante, uma cena genérica e uma cenografia. Examinemos o lugar de cada uma dessas cenas na reflexão do autor.

Com a produção de um enunciado, vemo-nos inevitavelmente diante de uma dupla cena: uma cena dita "englobante", que caracteriza o tipo de discurso em questão, e uma cena "genérica", que corresponderia às determinações dos gêneros do discurso. A título de exemplo, citemos o caso de diferentes tipos de panfletos distribuídos gratuitamente nas ruas: se é verdade que chamamos a todos de "panfletos", isto é, se neles reconhecemos uma mesma cena genérica, também é verdade que somos capazes de distinguir cenas englobantes diversas, uma vez que há panfletos que pertencem ao tipo de discurso publicitário (por exemplo, a publicidade de um novo condomínio ou de um produto de limpeza) e outros que pertencem ao tipo de discurso político (por exemplo, um panfleto de candidato em período eleitoral). Ao encontro dessas duas cenas o autor dá o nome de "quadro cênico", noção que define "o espaço estável no interior do qual o enunciado adquire sentido” (MAINGUENEAU, 2001, p. 87)

Uma vez traçada a diferença entre cena englobante e cena genérica, resta-nos introduzir a terceira modalidade de cena anunciada pelo autor: a cenografia. Segundo Maingueneau, a cenografia é o primeiro elemento com o qual se defronta o interlocutor, se considerarmos que ela é a cena instituída por cada enunciado. A exemplificação do lugar ocupado pela cenografia na reflexão do autor torna-se simples se recorrermos a enunciados do tipo publicitário. Com efeito, não é raro que um mesmo produto seja apresentado a seu potencial consumidor sob formas variadas: uma narração de eventos que introduza o produto em uma cena do cotidiano, uma explicação científica que enfatize as propriedades nutricionais do produto, uma conversa informal entre amigos que aconselham o produto, uma cena humorística, o depoimento de um artista famoso sobre as qualidades do 
produto, etc. Trata-se, em cada caso, de uma cenografia construída para um fim específico: a publicidade de um produto supõe, inicialmente, a existência de uma situação de enunciação que lhe daria sustentação (por exemplo, a situação de um evento narrado na vida de uma família que consome o produto anunciado), e essa mesma situação de enunciação vai, a seu turno, sendo aos poucos validada por intermédio da própria enunciação. Tal relação circular corresponde ao que o autor denomina "um processo de enlaçamento paradoxal” (MAINGUENEAU, 2001, p. 87): por um lado, a publicidade se apropria de valores positivos que circulam em uma dada cultura - por exemplo, o relacionamento, invariavelmente harmonioso, entre membros de uma família - para validar o que se pretende dizer acerca desse produto; por outro, o texto publicitário reafirma o lugar daquela mesma imagem de família como sendo o lugar legítimo de sua enunciação ${ }^{1}$. Por essa razão, o autor caracteriza a cenografia como uma espécie de cilada: o interlocutor do exemplo a que recorremos é interpelado enquanto integrante de uma cultura que valoriza as boas relações e o velho diálogo familiar, ao invés de o ser mais diretamente na qualidade de consumidor de um certo produto que se anuncia.

Para finalizar, acrescentemos que o autor estabelece uma possível "tipologia" dos gêneros do discurso em sua relação com as cenografias (MAINGUENEAU, 2001, p. 89-90): (i) gêneros, pouco numerosos, que se limitam à cena genérica, não permitindo cenog rafias variadas (a exemplo do catálogo de telefone, da receita médica etc.); (ii) gêneros que exigem a escolha de uma cenografia (gêneros publicitários, literários, filosóficos, etc.); (iii) gêneros "intermediários", que permitem cenog rafias variadas e que, no entanto, costumam na maioria das vezes "conformar-se" à cena genérica de rotina (guia turístico, por exemplo). É sobre essa tipologia tripartite e, em particular, sobre o caso dos gêneros que não se prestam a cenografias variadas que incidirá nossa atenção.

1. Nesse caso, a circularidade do enlaçamento paradoxal a que se faz referência parece colocar em cena um texto subreptício da seguinte ordem: por um lado, "as vantagens que se enunciam de um dado produto só podem ser efetivamente verificadas em um universo habitado por uma família que reúna as qualidades exibidas"; por outro, "uma família com tantas qualidades só poderia mesmo consumir um produto como o que ora se anuncia”. 


\section{Cenografia: ReSSignificANDO UM CONCEITO PLURAL}

Entendendo como bastante produtiva a proposta feita por Maingueneau de uma tríplice cena para pensar as questões ligadas aos gêneros do discurso, quero, no entanto, repensar o lugar ocupado pela cenografia diante do quadro cênico idealizado pelo autor. Argumentarei no sentido de rever a motivação de Maingueneau para sustentar a distância criada entre as "coerções de um dado gênero" e as "liberdades oferecidas pela cenografia”. Em outras palavras, procurarei diminuir a referida distância, reunindo argumentos que aproximem a cena genérica e a cenografia, visando, com isso, propor que, em graus variados de manifestação, um plano cenográfico sempre estará presente, acompanhando o chamado quadro cênico.

Antes, porém, quero aqui registrar um duplo modo de compreensão da noção de cenografia que se pode recuperar a partir da leitura de Maingueneau. Para tal fim, recorro a dois momentos da reflexão do autor no capítulo 7 de Análise de Textos de Comunicação, que tematiza a cena de enunciação.

Tomo primeiramente o exemplo da "Carta a todos os franceses", de Mitterrand, a qual fez parte dos documentos produzidos por ocasião da campanha presidencial de 1988 na França (MAINGUENEAU, 2001, p. 91-93). Aqui, há como que uma "metamorfose" do gênero discursivo: a fala do candidato à presidência da República se apresenta travestida de carta íntima distribuída a cada cidadão. E mais: uma carta íntima que recupera, na memória do cidadão francês, uma cena validada de grande importância para a captação e convencimento do leitor, a saber, a conversa em família durante a refeição.

Neste caso, temos um exemplo bastante claro do que o autor denomina a "cilada" da cenografia: o leitor tem como "porta de entrada" do texto algo que o faz pensar no gênero "conversa íntima" propiciada pela carta, e somente mais tarde se apercebe de que se trata de um panfleto de campanha eleitoral (cena genérica), gênero recorrente na cena englobante dos discursos políticos, ficando a carta íntima realocada no plano cenográfico. Em outras palavras, temos uma "superposição" de gêneros - a carta íntima "recobrindo" o panfleto de campanha -, e será preciso que a primeira seja reconhecida em sua função cenográfica para que o discurso político do panfleto produza os efeitos esperados enquanto efetivo gênero de discurso. 
Metamorfoses cumpridas: o enunciador da carta mostra sua face de candidato à presidência da república; o leitor é revelado em seu papel de eleitor; a carta íntima, mimetizando a conversa convivial em família ao redor da mesa, se deixa apreender como panfleto de campanha política.

Outra me parece ser a situação do encontro de uma cena genérica e de uma cenografia no caso do guia turístico intitulado Guide du routard apresentado pelo autor (MAINGUENEAU, 2001, p. 88-90). Aqui, não há exatamente o mesmo tipo de cilada decorrente do acionamento de uma cenografia: o leitor parece ter acesso direto ao próprio quadro cênico, uma vez que ele se dá conta desde o início de que está às voltas com o gênero "guia de turismo". O que ocorre então é um ligeiro - e, claro, não sem importância - deslocamento em um gênero considerado pelo autor como bastante estabilizado: ao invés de apagar as marcas de sua presença, como é costume acontecer nos guias de turismo, o enunciador inova, desenvolvendo uma outra encenação de sua fala ao privilegiar a conversa falada, descontraída, bem ao gosto dos mochileiros. Uma forma "atenuada", talvez, de metamorfose, de atualização da cenografia que vem propor um novo equilíbrio entre os coenunciadores desse guia.

Retomando o objetivo deste artigo, buscarei sustentar que é principalmente neste segundo sentido que entendo que um plano cenográfico sempre estará presente, acompanhando o quadro cênico: em graus variados de manifestação, a cenografia compreende desde os mais ínfimos deslocamentos da relação instituída entre os coenunciadores (como ocorre no guia turístico) até as metamorfoses mais substanciais, quando o próprio quadro cênico não mais pode ser percebido de imediato (como era o caso do panfleto de campanha eleitoral).

Para tal fim, recorro inicialmente à análise de um texto que ilustra de modo bastante conveniente a relação entre coerções genéricas e cenografia, explicitando algumas das pistas que permitem ao leitor ressignificar como investimento cenográfico aquilo que ele julgara de início corresponder a uma marca de gênero.

\section{Afinal, A Que Gênero Pertence este teXto?}

A articulação entre gênero do discurso e cenografia é geradora de perfis textuais bastante variados - e mesmo inesperados. Passemos à leitura de 
um desses textos em que o leitor leva algum tempo para distinguir a cena genérica e a cenografia.

Era uma vez ...

Era uma vez um Engenheiro de Telecomunicações que apesar de sua idade (cerca de trinta anos), possuía uma boa experiência em telefonia móvel, transmissão por satélite e por rádio e sistema de micro-ondas. Tinha domínio de informática (Windows, Word, Excel, Autocad), era habituado a trabalhar em ritmo acelerado e tinha bons conhecimentos de Inglês e Espanhol. E por achar que estava bem empregado, não deu importância ao anúncio de emprego que oferecia desafios, oportunidade de desenvolvimento e carreira, atraente remuneração e pacote de benefícios comuns a uma Empresa Multinacional.

Conclusão: Ele perdeu uma grande oportunidade e nós ficamos satisfeitos!

Porque buscamos, além dessas qualificações, profissionais altamente dedicados, habilidosos, capazes de superar desafios e com disponibilidade de viagens.

Não perca esta oportunidade!

Envie seu currículo especificando dados pessoais, formação, cursos de especialização, idiomas (nível), experiência profissional, empresa atual e remuneração com foto recente para caixa postal 21.230 - CEP.:20110-970 mencionando no envelope o código 8665.

Garantimos total sigilo.

A "mescla" de coerções que se apresentam nesse texto é bem evidente desde o início: era uma vez ... um engenheiro de telecomunicações?! Aparentemente, trata-se de um conto infantil - "era uma vez" -, mas com um protagonista nada convencional, se considerarmos que os príncipes e as princesas - e não os engenheiros - é que costumam ocupar tal posição. De qualquer modo, há ainda alguns outros indícios de que o que está em questão nesse texto pode ser relacionado aos contos de fadas: além do já mencionado "era uma vez", temos ainda uma profusão de verbos no imperfeito (que, nos contos, remetem a um tempo mítico), uma descrição de personagem (suas características, qualidades e hábitos), uma certa estrutura narrativa que, após o enfrentamento de dificuldades, permite retomar a fórmula do viver feliz para sempre (“e nós ficamos felizes”).

Há, por outro lado, marcas igualmente explícitas de um indiscutível distanciamento em relação ao conto de fadas: além da já mencionada presença inusitada de um engenheiro de telecomunicações como protagonista, é o enunciador, e não o protagonista da história, que conhece um "final 
feliz"; e mais: enunciadores de contos de fadas não oferecem oportunidades imperdíveis, nem solicitam o envio de currículo a seus coenunciadores!

Se falamos de um distanciamento em relação ao gênero conto de fadas, é porque somos capazes de reconhecer alguns dos dispositivos que caracterizam um outro gênero: o anúncio de emprego. Com efeito, é no contexto implicitado por esse outro gênero que passam a fazer sentido, por exemplo, a referência a um engenheiro de telecomunicações e a demanda de um currículo. No texto em análise, há ainda outros indicadores que confirmam sua inscrição no universo dos anúncios de emprego, como, por exemplo, as coordenadas do plano da dêixis empírica: o texto foi extraído de um jornal (a saber, Jornal do Brasil de 2 de maio de 1999), mais especificamente, da página 6 do caderno Empregos. Encontrava-se no mesmo espaço de outros textos inequivocamente reconhecidos como anúncios classificados. Essa contiguidade espacial é reveladora do tipo de texto com o qual lidamos, contiguidade essa que já se configura como uma "leitura" de quem organiza o jornal e, para tal, reúne textos em diferentes seções. Ora, considerando que o destinatário do Caderno Emprego deva ser um adulto que procura uma colocação no mercado de trabalho, não há qualquer explicação plausível para que alguém lhe dirija nada mais nada menos que ... um conto de fadas! Assim, o anúncio é o que permanece como forma primeira a ser identificada, como forma estável, após os momentos de estranhamento causados pela introdução "Era uma vez". Do mesmo modo que dizemos que o anúncio é a forma estável que prevalece, diremos que o conto de fadas é o deslocamento (ou a ligeira iniciativa de movimentação / deslocamento) de tal figura - uma tentativa de deslocamento que parece fadada ao fracasso, pois, no contexto em que o texto é publicado, dificilmente haveria o risco de não mais o reconhecermos como um exemplar de anúncio de emprego.

Seja como for, ainda que estejamos longe de passar a ver nesse texto um conto de fadas, tal deslocamento não deixa de produzir efeitos curiosos: por intermédio da ficção, constrói-se o perfil de um certo engenheiro ao qual o leitor do anúncio não deverá se identificar, tendo em vista a falta de ambição do personagem descrito, etc. Em outras palavras, o recurso ao conto de fadas parece garantir que apenas se apresentem como candidatos os engenheiros de telecomunicações que forem ambiciosos.

Eis, desse modo, o que nos leva a reconhecer no texto em questão o gênero "anúncio de emprego", sendo o conto de fadas remetido ao plano 
da cenografia, na qualidade de "cilada", como diz Maingueneau. Exatamente por essa razão ele foi escolhido para fins de análise neste tópico: um anúncio de emprego constitui um bom exemplo do que Maingueneau considera como gênero que não investe em cenografias, situação que, como foi visto, sempre poderá surpreender: pensando ler um conto infantil, o interlocutor é ludicamente introduzido no universo do trabalho, graças a uma cenografia que tem o mérito de desestabilizar o leitor pelo que há de inusitado no texto produzido.

\section{Por QUe RaZÃo PREFERIMOS APOSTAR NA ONIPRESENÇA DAS CENOGRAFIAS?}

Busco neste item reunir algumas das razões pelas quais prefiro não acolher uma tipologia textual que inclua a categoria "textos que se limitam ao cumprimento de sua cena genérica, não sendo suscetíveis de adotar cenografias variadas" (MAINGUENEAU, 2001, p. 89), por considerar mais produtivo pensar que o investimento cenográfico sempre estará presente na produção dos textos, variando apenas seu grau de visibilidade.

É no confronto com a forma "conto de fadas" que se percebe o que há de cristalizado na forma "anúncios classificados". Com efeito, o inusitado do anúncio transcrito se deixa apreender quando o contrapomos à forma mais recorrente que esse tipo de texto costuma assumir nos jornais:

Engenheiro de telecomunicações $c /$ experiência mínima de 3 anos, empresa do ramo contrata p/ início imediato. Interessados enviar currículo p/ e-mail: xxx@zz.com.br.

A escrita concisa, com o uso de abreviações e restringindo-se ao mínimo indispensável, é evidentemente uma importante estratégia de barateamento dos custos do anúncio. Trata-se, pois, de um "perfil" textual que se construiu aos poucos e que se estabilizou em uma forma mais ou menos padrão, a qual hoje é tida como fazendo parte das coerções do gênero. No entanto, sabemos que os gêneros têm uma história que se modifica com o tempo, ao sabor das novas situações de produção textual que vão surgindo.

Considerar a forma "anúncio de emprego" como desprovida de cenografia é naturalizar algo que foi sendo aos poucos construído, tomando por origem o que, na realidade, é efeito. Para tratar a questão da articulação 
entre gênero e cenografia, apresentamos inicialmente um ponto de vista do qual nos afastamos, para, a seguir, afirmar o enfoque que nos parece ser mais adequado. Nesse sentido, preferimos não assumir que:

- as coerções genéricas sejam anteriores à escolha de uma cenografia e que, por esse motivo, existam gêneros que permitem ou não um investimento diversificado no que diz respeito à cenografia;

- as coerções genéricas representem algo da ordem do essencial, cabendo à cenografia um lugar acidental;

- as coerções genéricas sejam da ordem do social, diferentemente da cenografia, expressão de uma individualidade.

Ao contrário, propomos que tanto o gênero quanto a cenografia são forças mais ou menos formalizadas que se confrontam na enunciação, entendida como relação entre coenunciadores num dado tempo e num dado espaço, com base em um certo suporte, etc. No que diz respeito ao exemplo com o qual trabalhamos, quando falo do confronto de forças - anúncio de emprego e conto de fadas -, entendo que o polo "anúncio" ganha contornos mais nítidos, isto é, configura-se como forma reconhecível que predomina sobre o polo "conto de fadas". Em outras palavras, apesar das marcas que remetem ao conto infantil, o coenunciador deverá receber o texto como um anúncio de emprego (forma mais fortemente visível, espacializada) e não como conto de fadas (forma menos espacializada, remetendo a uma tentativa de movimentação ou deslocamento da forma "anúncio"). Haverá, desse modo, uma gradação que vai das formas mais fortemente espacializadas (gêneros) a formas menos espacializadas (investimentos cenográficos), que funcionam como forças de alteridade - menos nítidas no espaço e mais fugidias no tempo (DELEUZE, 1962; MOSÉ, 2005).

Acredito que tal ponto de vista tenha o mérito de corresponder à própria natureza daquilo que denominamos gêneros. Sabemos que, enquanto totalizações, não há gêneros puros, e que toda e qualquer "identidade" nesse sentido só pode ser um efeito do interdiscurso ${ }^{2}$; o que há são variações que se aproximam mais ou menos de uma certa forma que reconhecemos como um gênero particular. As fronteiras entre gêneros são tênues, sendo, por

2. A posição que aqui assumo é compatível com a questão das intertextualidades no plano dos gêneros (intergenericidade) de que falam, dentre outros, Fix (2006), Marcuschi (2008), Lima-Neto \& Araújo (2012). 
isso, previsível que um dado texto se apresente em maior ou menor grau de conformidade com aquilo que consideramos como um protótipo de um certo gênero. Assim sendo, investir em um gênero (isto é, investir em uma forma mais estabilizada) é necessariamente investir em forças em oposição (ou seja, investir em cenografias). Tal embate de forças / formas pode ter graus de visibilidade variados: pode haver uma maior ou menor exibição da presença desse elemento de alteridade que vem ressignificar as formas mais estáveis. Nos casos de menor visibilidade dessas forças desestabilizantes, a impressão é a de que o gênero se apresenta em estado "puro", desprovido de qualquer cenografia.

A esta altura do presente debate, considero oportuna uma breve digressão para acolher algumas das questões que já se anunciam como polêmicas $^{3}$, antecipando, desse modo, argumentos que alimentarão uma necessária interlocução. Com efeito, o leitor deste artigo poderá estar se indagando - justificadamente - a respeito de dois pontos: (i) a formulação teórica de Maingueneau referente à situação dos gêneros que não admitem cenografia seria uma formulação problemática, ou teria o autor apenas escolhido exemplos inadequados para ilustrá-la?; (ii) teria este artigo por objetivo sugerir que a presença de cenografias seja uma condição essencial a que deve atender um gênero discursivo para ser efetivamente dialógico?

Em resposta a tais questionamentos, começarei dizendo que o percurso teórico de Maingueneau é tão problemático quanto qualquer outro percurso produtivo no campo dos estudos discursivos, tomando-se aqui a palavra problemático na acepção de "não decisivo, sujeito a interferências, complicações". Com isso, quero dizer que o autor oferece respostas satisfatórias a algumas questões e deixa em aberto outras tantas. O que, aliás, não surpreende. Se acompanharmos o depoimento de Deleuze em seu diálogo com Foucault, diremos que um percurso teórico é sempre local, isto é, sempre relativo a um certo domínio e não tem qualquer compromisso com a aplicação de uma prática:

Por um lado, uma teoria é sempre local, relativa a um pequeno domínio e pode se aplicar a um outro domínio, mais ou menos afastado. A relação de aplicação nunca é de semelhança. Por outro lado, desde que uma teoria penetre em seu próprio domínio encontra obstáculos que tornam necessário que seja revezada por outro tipo de discurso ... A prática é um conjunto de revezamentos de uma teoria a outra e a

3. As observações que se seguem constituem a resposta que ofereço a questões efetivamente formuladas pelo parecerista deste artigo, cuja leitura atenta e produtiva só posso agradecer. 
teoria, um revezamento de uma prática a outra. Nenhuma teoria pode se desenvolver sem encontrar uma espécie de muro, e é preciso a prática para atravessar o muro. (FOUCAULT, 2008, p. 69-70)

A reflexão transcrita permite recolocar a relação que se estabelece entre teoria e prática como sendo não da ordem da aplicação, mas da ordem dos revezamentos. No caso específico do encontro entre teoria e prática que tematizo neste artigo - a articulação entre gênero / cenografia segundo Maingueneau e a produção de textos em que se atualiza tal articulação -, é bem verdade que anúncios classificados são muito mais estáveis (do ponto de vista sincrônico) do que publicidades, o que acaba criando como efeito uma autossuficiência teórica, uma espécie de certeza inabalável da ausência de cenografias em determinados gêneros. Em outras palavras, a referida certeza teórica dispensaria, de certo modo, a necessidade de qualquer revezamento com a prática, pois não chegaria a enxergar os muros que, retomando a metáfora deleuziana, seria preciso transpor.

Essa autossuficiência teórica é, sob uma outra perspectiva, ilusória, até mesmo porque uma formulação teórica não pode simplesmente se substituir à prática, falando em seu lugar. E não poderia ser diferente, se lembrarmos que uma teoria não tem o compromisso de ser uma "tradução" da prática, pelo simples fato de que a teoria já é uma prática - uma prática de luta contra poderes instituídos, dirá Foucault (2008, p. 71), uma luta contra a cristalização de verdades totalizadoras. Se esse é o caso, então, qual é a luta em que se engaja Maingueneau quando propõe gêneros de diferentes graus (MAINGUENEAU, 2006, p. 150-151), compreendendo desde os que não se submetem a variações cenográficas até aqueles que parecem não possuir qualquer formato pré-estabelecido?

A meu ver, uma luta contra uma concepção endurecida de gênero que deixasse de refletir a diversidade de fenômenos passíveis de serem englobados na rubrica "gêneros". Por essa razão, diante da heterogeneidade de fenômenos a que me refiro, Maingueneau (2006, p. 146) insiste inicialmente em uma classificação bipartite ("gêneros conversacionais" e "gêneros instituídos”) para, a seguir, especificar ainda mais tal heterogeneidade ao propor uma gradação que vai dos gêneros de primeiro grau (aqueles que abrem mão de qualquer cenografia) aos de quinto grau (textos autorais). Assim, é para combater uma concepção homogeneizante de gênero que o 
autor propõe uma tipologia que inclui, em um de seus polos, os textos ditos desprovidos de cenografia.

Se, a meu turno, prefiro falar de cenografias sempre presentes e mais ou menos cristalizadas, é porque a "luta" em que me engajo é outra: meu objetivo é pensar de que modo se dá a produção de indivíduos a partir do embate de forças - forças que se estabilizam, produzindo formas reconhecíveis, mas que nunca se anulam por completo, abrindo lugar para a produção do devir. Aliás, não é gratuito o que já se anuncia no título do artigo: uma cartografia pretende ser um método para acompanhar processos, produzindo um plano coletivo de forças que, em última instância, responderia pela gênese das formas empíricas individuadas. (PASSOS; KASTRUP; ESCÓSSIA, 2010). Desse modo, a objetivos diversos, formulações diversas. Afinal, reafirmando uma convicção deleuziana, uma teoria deve ser vista como "uma caixa de ferramentas", e o essencial é que ela funcione.

Quanto à segunda questão sugerida na reflexão do leitor, responderei apenas que é certo que as cenografias funcionam como marcas dialógicas de mobilidade de um gênero, mas estão longe de ser as únicas (ou mesmo as mais evidentes). Um breve exame da proposta de semântica global de Maingueneau (2005) será suficiente para circunscrever o lugar ocupado pela cenografia em meio à diversidade de dispositivos que, articulados, conferem seu tom a um texto.

Em função de todo o exposto, retomo o debate referente à articulação entre gênero e cenografia, ratificando algumas das posições que ora assumo:

- considerar que o gênero antecede a cenografia, podendo dela abrir mão, é consagrar uma perspectiva de hierarquias totalizantes;

- considerar que o gênero é o que é essencial, em contraposição à cenografia, elemento acidental, é opor o que é (o verdadeiro) ao que não é (o falso), posição característica das lógicas binárias que animam a modernidade;

- considerar que o gênero é social e a cenografia é individual implica criar uma falsa oposição, desconhecendo-se como funcionam os modos de produção de subjetividade (GUATTARI, 1992). 


\section{A ReCEITA MÉdicA: MALGRÉ tout, UM GÊNERo CAPAZ DE SE MOVER}

Em diferentes momentos de sua reflexão teórica, Maingueneau cita a receita médica como exemplo de gênero que se conforma a uma rotina, isto é, um gênero que não investe em cenografias ${ }^{4}$. O que queremos exatamente dizer quando sustentamos que um gênero não é suscetível de investir nessa terceira cena que é a cenografia? Buscaremos, a seguir, reunir elementos para abordar a questão colocada e traremos informações acerca da constituição da receita médica enquanto gênero; finalmente, ofereceremos algumas evidências de que, por refratária que seja a receita médica a deslocamentos na aparente fixidez do gênero, sempre será possível nela apreender traços que dão prova de cenografias em processo.

\subsection{O imobilismo atribuído ao gênero}

A receita médica é, com certeza, um gênero que apresenta maior estabilidade em relação a outros como, por exemplo, a publicidade, por razões que lhe são específicas: primeiramente, é um gênero estável porque é produzido por uma categoria bem circunscrita de locutores (no Brasil, médicos, veterinários, dentistas) e concerne diretamente à interlocução entre três - e apenas três - categorias de sujeitos (o médico, o cliente e o farmacêutico); não é um gênero que tenha por objetivo o convencimento de um coenunciador; do ponto de vista de sua composição, é fortemente submetido a uma normatização que, por razões de segurança, recorre à formulação de leis; finalmente, do ponto de vista gráfico-informacional perspectiva que inclui a análise do formato, dos elementos visuais e verbais de uma receita -, trata-se também de um gênero de características essenciais facilmente detectáveis (MARTINS, 2009, p. 48).

Porém, o ato de prescrever é mais complexo e diversificado do que poderia parecer, razão pela qual passamos a traçar-lhe um breve perfil. Trata-se de um ato que não é autônomo, configurando-se como um momento preciso de uma situação de trabalho que exemplifico com trecho de um Manual do Prescritor (UFRGS - HOSPITAL DAS CLÍNICAS, s.d.):

4. O autor também dá como exemplos de gêneros sem cenografia a lista telefônica, a correspondência administrativa e os relatórios de expertise (MAINGUENEAU, 2001, p. 88). 
Segundo a OMS, o processo de prescrição compreende seis etapas:

$1^{a}$ etapa: Coleta das informações do paciente, definição do problema e diagnóstico

$2^{a}$ etapa: Definição dos objetivos terapêuticos

$3^{\mathrm{a}}$ etapa: Seleção do tratamento

$4^{\mathrm{a}}$ etapa: Prescrição de medidas medicamentosas e/ou não medicamentosas

$5^{a}$ etapa: Informação do paciente

$6^{\text {a }}$ etapa: Monitoração do tratamento

Assim, percebe-se que a receita médica corresponde à quarta etapa de um processo. Trata-se de etapa que se submete a coerções que visam assegurar o sucesso da consulta médica e, por isso, seu grau de normatização é mais ou menos acentuado em cada cultura. Com efeito, seguem os elementos que minimamente devem constar em uma receita médica, segundo o referido manual:

- Identificação do paciente: nome completo e número do prontuário.

- Nome, forma farmacêutica e concentração do fármaco prescrito.

- Esquema de administração, incluindo via/método de administração, intervalo de doses, critérios para início ou suspensão.

- Cuidados na administração: por exemplo, "com alimentos" ou "longe das refeições"; "manter o paciente sentado por 30 minutos após ingestão"; "após hemodiálise’ etc.

- Outras recomendações podem ser colocadas no verso da receita.

- Nome completo do prescritor, assinatura de próprio punho e carimbo, onde deve constar o número de seu registro no respectivo conselho profissional.

- Data.

(UFRGS - HOSPITAL DAS CLÍNICAS, s.d.) 
Daí resulta uma dura "tipologia textual" de receitas médicas: receitas simples; receitas de controle especial (em duas vias, uma vez que uma delas fica retida com o farmacêutico); receita azul ou receita B (um impresso, padronizado, na cor azul, utilizado na prescrição de medicamentos que contenham substâncias psicotrópicas, válida por 30 dias a partir de sua emissão apenas na unidade federativa que concedeu sua numeração); receita amarela ou receita $\mathrm{A}$ (um impresso, na cor amarela, para a prescrição dos medicamentos entorpecentes e psicotrópicos, válida por 30 dias, a contar da data de sua emissão, em todo o território nacional); receita especial de retinoides, com validade de 30 dias e somente dentro da unidade federativa que concedeu sua numeração; receita especial para talidomida, válida por apenas 15 dias; finalmente, formulário próprio para substâncias antirretrovirais estabelecido pelo programa de DST/AIDS. (UFRGS - HOSPITAL DAS CLÍNICAS, s.d.)

Pressentimos, contudo, que a estabilidade exibida inicialmente por esse gênero recobre uma variação que se apresenta, é certo, dentro de limites, mas ainda assim suficientemente visível.

\subsection{Histórico das prescrições médicas}

As receitas médicas têm uma história que nos cabe no momento recuperar, ainda que apenas em seus traços essenciais. Tal história encontra-se imbricada com a própria história das profissões de médico e de farmacêutico, como veremos.

Houve um longo período no qual aquele que exercia a função médica acumulava também as funções de cultivar, preparar e administrar plantas medicinais. Aos poucos, já no contexto europeu do século XII d.C., esse "personagem" se fraciona em duas funções distintas - o médico, mestre na arte de curar, e o apotecário ${ }^{5}$, mestre na arte de preparar e administrar os medicamentos. Tal fracionamento justifica-se pela diversidade de funções que se acumulavam e a diversificação dos saberes que aos poucos se produziam na área.

5. Dou preferência à forma "apotecário", em detrimento de "boticário", para permanecer mais próximo à origem da palavra (do latim apothecariu, encarregado de depósito, farmacêutico, com base no grego apothéke, depósito). 
Datam de 1271 as primeiras leis que proíbem os apotecários de fornecer medicamentos, com exceção dos remédios mais comuns, sem a presença de um médico. Não existia, então, a receita médica escrita; o médico prescrevia oralmente, na presença do apotecário, as substâncias que deveriam entrar na composição dos medicamentos. Em sua versão escrita, a receita médica na França data de 1322, quando, em um édito, o rei proibiu os apotecários de vender ou oferecer medicamentos sem uma prescrição médica. Reforçando tal decisão, em 1353, o rei de França, Jean II, acrescentou que candidatos ao exercício da função de apotecário deveriam saber ler.

Em 1777, Luiz XVI determina a substituição do nome de apotecário pelo de farmacêutico - o termo "apoteca" permanece, contudo, em línguas como o alemão, o sueco, o russo e o polonês. A obtenção do diploma de farmacêutico exigia estudos teóricos e prestação de exames práticos, ainda que esse profissional não fosse considerado de nível universitário. Uma lei de 21 de abril de 1803 reafirmará a necessidade de uma receita médica (com assinatura) para que o farmacêutico possa distribuir medicamentos. Uma outra lei de 1845 mencionará pela primeira vez a obrigatoriedade de uma assinatura, de uma data e da especificação por extenso das substâncias prescritas, da dose indicada e do modo de administração de cada remédio.

Interrompo aqui o histórico esboçado, uma vez que, em cada país, a normatização progressiva da receita médica nos últimos séculos seguirá um caminho próprio - detalhamentos que não farão no momento o objeto de nossa atenção. O que ora interessa retomar é a temática dos deslocamentos - por mínimos que possam parecer - em diferentes dispositivos discursivos ao longo da constituição de um gênero, deslocamentos que nos permitirão captar o surgimento de cenografias.

\subsection{Diacronia dos investimentos cenográficos nas receitas médicas}

Tomemos como ponto de partida a "pré-história" das receitas médicas: praticamente invisíveis, as receitas se confundiam com o fazer do médicoapotecário, isto é, não chegavam a ganhar materialidade enquanto produção textual, pois faziam parte de um know-how que o profissional demonstrava no instante mesmo em que o executava. 
A seguir, o que percebemos é a relevância do processo de autonomização progressiva da receita médica, quando se separam as figuras do médico e do apotecário. A receita médica parece, com efeito, ganhar visibilidade como texto que se produz no momento em que o profissional que idealiza e prescreve uma dada forma de tratamento não mais coincide com aquele que irá preparar e distribuir o medicamento. Em um primeiro momento, um gênero que, como ficou assinalado, se atualizava tão somente na modalidade oral, o que implicava o deslocamento espacial do médico até a oficina do apotecário para coordenar a preparação do medicamento; depois, a modalidade que se afirmou com o tempo, segundo a qual a prescrição médica passou ao registro escrito, o que possibilitou uma maior independência do paciente, que poderia passar a fazer contato direto com o apotecário, apresentando-lhe o "documento" que lhe autorizaria encomendar e consumir uma dada fórmula terapêutica.

De sua produção “internalizada", como "segredo" do próprio médico que preparava o medicamento, ao texto oral negociado entre médico e apotecário e, a seguir, do texto oral à sua inscrição no papel apresentado pelo paciente ao apotecário, assiste-se a alterações no plano cenográfico que mobilizam minimamente, como dispositivo discursivo, o lugar ocupado pelos coenunciadores: (i) atualização de uma cenografia de reflexão introspectiva na coincidência do médico-apotecário em seu silencioso trabalho de idealização e preparação da droga terapêutica; (ii) relação direta entre médico e apotecário, ambos empenhados em um trabalho conjunto de preparação do medicamento; (iii) relação indireta entre médico e apotecário, possibilitada pela inscrição da receita em suporte papel; (iv) relação direta entre paciente portador de receita em suporte papel e apotecário, executor das orientações constantes na inscrição, distanciando-se no tempo e no espaço o momento da prescrição e o da preparação / dispensação do medicamento.

Um breve exame de modos outros de atualização da receita médica em diferentes culturas restitui-lhe aquilo que, para além de sua aparente fixidez, ela pode apresentar como elementos em variação e que, por essa razão, concerne a diferentes investimentos cenográficos.

Comecemos pelo caso em que se assiste ao investimento em um código de linguagem, em uma cronografia e na relação entre coenunciadores. Não é difícil perceber que o investimento em um código de linguagem é bastante marcado em toda a área médica. De modo geral, podemos dizer 
que o recurso a radicais, prefixos e sufixos gregos e latinos tem por objetivo garantir maior precisão do significado das palavras e facilitar o intercâmbio científico entre as nações que falam diferentes línguas. Tomemos como exemplo o termo esplenomegalia, que significa "baço aumentado de tamanho". A palavra compõe-se das raízes gregas splén (baço) + megalo (grande) + sufixo $i a$. Trata-se de um termo universal, comum a todos os idiomas, e isso facilita muito a intercompreensão, o que não ocorreria caso o nome dado à anomalia tomasse por base a palavra "baço" em cada língua (spleen, em inglês; mitz, em alemão; rate, em francês; milza, em italiano; bazo, em espanhol e baço, em português).

Se o recurso a um código de linguagem apresenta tais vantagens, é certo também que ele cria um fosso - via de regra, intransponível - entre os coenunciadores: de um lado, o médico erudito; de outro, o paciente leigo. Tal é o caso em particular do recurso a abreviações em latim usadas em receitas médicas de países que têm o inglês como principal língua materna. Por exemplo, tomemos o seguinte enunciado típico de uma prescrição médica (ABOUT.COM. s.d.):

R I tab po qid pc \& hs

O enunciado é incompreensível se não temos acesso às seguintes informações:

$\mathrm{R}_{\mathrm{l}}($ ou $\mathrm{Rx})$ - abreviatura do latim "recipe", imperativo de "recipere", "tomar", "fazer uso de"

tab (tabella), "tablete"

po (per os), "pela boca" ou seja, "via oral"

qid (quater in die), "4 vezes ao dia"

pc (post cibum), "após as refeições"

hs (bora somni), "ao deitar"

Assim, o enunciado se torna mais claro: "Tome 1 tablete via oral 4 vezes ao dia, após as refeições e ao se deitar".

Não é preciso acentuar que o recurso ao latim como língua de base para a prescrição médica implica ainda, por extensão, um investimento na cronografia. Com efeito, a presença do latim é testemunha de um tempo 
passado em que essa era a língua na qual era lícito fazer ciência e filosofia. Sua presença em receitas médicas da atualidade mimetiza uma sabedoria que esteve reservada a poucos, conferindo respeito e distinção a seus doutos usuários.

\subsection{Cenografias da contemporaneidade}

Para finalizar este item, quero acrescentar de modo sucinto dois casos que representam um investimento certo no plano cenográfico das receitas médicas na atualidade, pelo fato de trazerem à cena um deslocamento respaldado em práticas de natureza intersemiótica (Maingueneau, 2005).

O primeiro caso diz respeito à reprodução de uma receita médica datada de 10/08/2007 no blog venezuelano Venezuela News and Views. Ao prescrever um hemograma, a receita parece limitar-se a respeitar suas coerções genéricas, abrindo mão de qualquer elemento de variação, se não fosse um pequeno detalhe que faz toda a diferença: no centro do papel, como marca d'água, a imagem de Hugo Chávez ao lado de Fidel Castro (VENEZUELA NEWS AND VIEWS, 2012). Por intermédio de uma prática intersemiótica que conecta o verbal, o gráfico e a imagem, o texto reproduzido não deixa de trazer importantes consequências para o estatuto de seus coenunciadores: mediante o encontro dos discursos médico e político, os coenunciadores não são apenas o médico, o paciente e o farmacêutico, mas cidadãos que compartilham uma escolha política de aliança nacional com o presidente cubano que, aliás, encontra-se naquela ocasião com a saúde bastante debilitada.

Um último caso de investimento cenográfico pelo recurso a uma prática intersemiótica é o de uma receita médica prescrita por uma médica atuando em um posto de saúde na cidade de Tiradentes, Minas Gerais (MACHADO, 2010). Diante da realidade de sua clientela, composta de analfabetos que tinham dificuldade de compreender suas prescrições, a médica passa a conjugar em suas receitas, ao lado das indicações da ordem do verbal, desenhos, símbolos e colagens que deverão facilitar a tarefa de leitura de suas prescrições. Assim, para que não haja dúvidas, o enunciador apõe ao nome do medicamento um comprido, cujo formato e cor serão memorizados pelo paciente. Da mesma forma, para indicar o horário em que deve ingeri-lo, faz o desenho de um sol nascente ou de uma lua. Os 
diferentes sistemas semióticos que se conjugam na receita distinguem, de modo inequívoco, seus coenunciadores: ora o enunciador-médico se dirige ao farmacêutico que aviará a receita ( $\mathrm{e}$, nesse caso, é a linguagem verbal que entra em cena), ora se dirige ao paciente que não sabe ler (e que, por isso, tomará por referência principalmente as marcas visuais deixadas pelos desenhos e colagens).

\section{7. (IN)CONCLUSÕES}

Para concluir este debate que problematiza dispositivos da ordem da interdiscursividade, quero aqui retomar a questão levantada em Charaudeau \& Maingueneau (2004, p. 251) sobre quão diversos são os critérios que nos permitem falar de gêneros. A esse respeito, lembro apenas dois desses critérios que importarão em nossa reflexão: as regularidades composicionais dos textos e a ancoragem social do discurso. Quando um gênero é definido a partir do primeiro desses critérios, priorizamos uma abordagem dos "gêneros de texto"; quando, ao contrário, enfocamos em nossa abordagem a ancoragem social como critério definidor dos gêneros, então chegamos a uma tipologia dos "gêneros de discurso". Quero aqui reafirmar a escolha que faço: investir na ideia de gêneros de discurso. Apresentarei argumentos sobre o porquê dessa escolha.

Ao trabalhar com o texto "Era uma vez um engenheiro de telecomunicações ...", enfatizamos, é certo, a materialidade linguística que nos trazia pistas ambíguas, no sentido de ali encontrarmos indícios de textualidades diversas: o introdutor "era uma vez", acompanhado de uma descrição de personagem com verbos no imperfeito, etc., marcas que remetiam inequivocamente a um perfil textual que chamamos de conto de fadas, ao lado de formas no imperativo que interpelavam o interlocutor, incitando-o a fazer algo e oferecendo-lhe um tempo futuro vantajoso, marcas que atribuímos então a um outro perfil textual que denominamos anúncios classificados de emprego. Não foi difícil decidir por um dos perfis textuais então criados: tratava-se de texto publicado no Caderno de emprego de um jornal de grande circulação, ao lado de outros textos que também se reportavam ao mundo do trabalho. Estava decidido que se tratava de um anúncio de emprego. 
Não seria difícil, no entanto, imaginar um outro lugar de emergência para aquele mesmo texto: ao invés de sua publicação em um jornal de grande circulação, a intimidade da leitura realizada pela mãe no silêncio da noite, em resposta à demanda da criança que promete dormir após ouvir a história. Nesse caso, ainda que pudéssemos considerar bizarra a aventura narrada, não mais seria possível traçar-lhe o perfil de um anúncio de emprego, sendo, então, imperativo nele reconhecer um conto de fadas. E qual teria sido o elemento decisivo para tal mudança de gênero? Com certeza, não a materialidade textual, que seria a mesma em ambos os casos, mas a situação na qual o texto se atualiza. Eis por que considero preferível pensar os gêneros como uma propriedade discursiva.

Outros exemplos do mesmo tipo poderiam ainda ser lembrados. Se arrancássemos uma página de Bolor, romance de 1968 do autor português Augusto Abelaira, e a transcrevêssemos a mão, talvez não fosse possível reconhecer com segurança de que gênero se trata: texto literário ou página de diário íntimo? Com certeza, o acesso apenas a uma materialidade linguística, impedindo-se o conhecimento das condições em que os textos são produzidos e circulam entre seus coenunciadores, é fator de indefinição de um perfil genérico.

Um último exemplo que me parece extremamente elucidativo. Tomemos conhecimento do seguinte texto, sem que se anuncie qualquer pista concernente ao contexto em que ele surge:

\section{RELATO EMOCIONADO:}

\section{"EU NUNCA NEGUEI QUE VIM DE BAIXO."}

A materialidade textual nos permite o acesso a uma forma de discurso relatado, no qual se encontram a voz do discurso citante (Relato emocionado) e do discurso citado em estilo direto, entre aspas ("Eu nunca neguei que vim de baixo"). À primeira vista, parece plausível a hipótese de uma manchete de jornal em que se entrevista uma celebridade qualquer que faz uma retrospectiva de sua vida, tendo como ponto de partida as origens humildes que não pretende esconder do público. Diferentemente da expectativa criada, passemos, então, ao contexto em que esse enunciado foi efetivamente proferido, e o gênero inicialmente imaginado (manchete de jornal ou de revista de grande circulação) se reconfigurará para dar lugar a um outro do qual talvez jamais pudéssemos suspeitar. Trata-se de um 
enunciado que acompanhava a imagem de uma beterraba, publicado na primeira página do panfleto publicitário distribuído por um hortifruti. $\mathrm{O}$ projeto de produzir um efeito de humor na publicidade da loja é evidente, tendo em vista a sensação de "depoimento" prestado pela beterraba que, como todo tubérculo, só pode ter vindo de baixo (da terra!).

Reafirmada minha opção de que os gêneros são mais adequadamente tratados como fenômenos discursivos, o que ora desejo enfatizar é o embate de forças que acaba sendo responsável pelo que será apreendido como gênero e como cenografia.

Apesar da relativa estabilidade dos enunciados - base bakhtiniana para definir a noção de gênero (BAKHTIN, 1992, p. 279) -, sua mobilidade é, no entanto, um traço que sempre se atualiza, seja por intermédio do referido embate de forças que acaba designando o lugar ocupado pelas cenografias, seja pela constatação de que diferentes formações discursivas investirão de modos diferenciados naquilo que costumamos reconhecer como um "mesmo" gênero.

A proposta de abordagem do confronto entre gêneros e cenografias deste artigo tomou por base um duplo entendimento possível da função das cenografias: ora atuando como cilada, como encobrimento do quadro cênico, para retomar a formulação de Maingueneau, ora produzindo discretos deslocamentos que têm por efeito produzir um certo estranhamento em relação ao que há de mais cristalizado em um gênero. Neste segundo caso, preferiu-se entender que a distância que separa gêneros e cenografias é da mesma ordem da distância que distingue formas (estabilizadas no tempo e no espaço) e forças (em efervescência). Com efeito, formas constituídas acabam sendo impotentes diante de forças em movimento. A dinâmica entre formas constituídas (gêneros) e forças (investimento cenográfico) poderá ser mais claramente apreendida por intermédio de uma comparação com o que se transcreve no fragmento a seguir, o qual versa sobre o embate entre as formas (do conhecimento) e as forças (da invenção):

[as invenções] não resultam de atos isolados de criação. Elas existem, elas passam a existir, como o resultado de um ato de força, de imposição de sentido. As forças, por sua vez, tampouco existem ou agem isoladamente. Elas estão em ação em um campo de forças, o que significa dizer que uma força age sobre outra força, que aquilo que as movimenta é a diferença entre uma força e outra. É essa diferença que faz a diferença entre uma invenção e outra. As forças dão forma às criações, imprimem nelas sua marca, sua diferença. 
Conceber o conhecimento em termos de interpretação e de correlação de forças significa renunciar a qualquer busca pela "coisa-em-si”.

(SILVA, 2002, p. 9)

Uma última observação deverá ser suficiente para suspender no momento um debate que ainda provocará muita reflexão. Vimos que a história das profissões de médico e farmacêutico havia desempenhado um papel fundamental na própria constituição do gênero "receita médica". Pôde-se, com efeito, constatar que o surgimento da receita médica como gênero (discursivo) não representa senão a contraface da organização de grupos (o grupo dos médicos e dos farmacêuticos) - uma história que vai da coincidência das duas funções na pessoa de um mesmo profissional ao desdobramento e consolidação progressiva de duas profissões distintas. Ora, o que parece relevante aqui é que tal imbricação entre vida social dos grupos e produção textual não faz senão reafirmar exemplarmente um conceito que recuperamos logo ao início deste artigo: o conceito de prática discursiva (MAINGUENEAU, 1989, p. 56), entendido como a interdependência de uma produção de textos e da formação de uma comunidade que dá à luz esses textos, ao mesmo tempo em que deles também recebe visibilidade. Um debate que, desse modo, potencializa a presença do analista do discurso na qualidade de cientista social.

Recebido em outubro de 2012 Aprovado em janeiro de 2013 E-mail: rochadm@uol.com.br

\section{REFERÊNCIAS}

ABOUT.COM. s.d. Understandig Prescription Abbreviations. Disponível em: arthritis.about. com/od/arthritismedications/f/rxabbreviations. htm. Acesso em: 22/09/2012.

Bakhtin, Mikhail. 1992. Estética da criação verbal. São Paulo: Martins Fontes.

Deleuze, Gilles. 1962. Nietzsche et la philosophie. Paris: PUF.

FIX, Ulla. 2006. O cânone e a dissolução do cânone. A intertextualidade tipológica - um recurso estilístico "pós-moderno"? Revista de Estudos da Linguagem, Belo Horizonte, v. 14, n. 1., p. 261-281, jan./jun.

Foucault, Michel. 2008. Microfísica do poder. Rio de Janeiro: Graal. 
Guattari, Félix. 1992. Heterogênese. In: Caosmose - um novo paradigma estético. São Paulo: Ed. 34.

Lima-Neto, Vicente; Araújo, Júlio César. 2012. Por uma rediscussão do conceito de intergenericidade. Linguagem em (dis) curso vol.12 no. 1 Tubarão SC: Universidade do Sul de Santa Catarina. Jan./Apr.

MACHADO, Lívia. 2010. Receita médica com colagem e ditado. In: IG. Seção Último Segundo / Brasil. Disponível em: ultimosegundo.ig.com.br/ brasil/receita + medica + com + colagem +e + ditado/n1237768999584. html. Acesso em: 22/09/2012.

Maingueneau, Dominique. 1989. Novas Tendências em Análise do Discurso. Campinas, SP: Pontes.

. 1998. Termos-chave da Análise do Discurso.Belo Horizonte: Ed. UFMG.

. 2001. Análise de Textos de Comunicação. São Paulo: Cortez. . 2005. Gênese dos discursos. Curitiba: Criar. . 2006. Cenas da enunciação. Curitiba: Criar.

Marcuschi, Luiz Antonio. 2008. Produção textual, análise de gêneros e compreensão. Rio de Janeiro: Parábola Editorial.

Martins, Ricardo. 2009. Análise gráfica de receitas médicas. Curitiba, PR. Dissertação de Mestrado. Universidade Federal do Paraná, 96 p.

Mosé, Viviane. 2005. Nietzsche e a grande política da linguagem. Rio de Janeiro: Civilização Brasileira.

Passos, Eduardo; Kastrup, Virgínia; Escóssia, Liliana da. 2010. Pistas do método da cartografia - pesquisa-intervenção e produção de subjetividade. Porto Alegre: Sulina.

SiLva, Tomás T. da. 2002. Dr. Nietzsche, curriculista - com uma pequena ajuda do Professor Deleuze. In: Moreira, Antonio, MAcedo, Elizabeth F.(Orgs.) Currículo, práticas pedagógicas e identidades, Porto: Porto editora. Disponível em: www.cefetes.br/gwadocpub/Pos-Graduaçao/ Especializaçao em educaçao EJA/Publicaçoes/anped2001/textos/ t1299570907599. PDF. Acesso em: 24/09/2012.

UfRgs - hospital Das Clínicas. s.d. Manual do Prescritor. Disponível em: www.hcpa.ufrgs.br/downloads/academico/manual_do_prescritor_2. pdf. Acesso em: 16/09/2012.

VENEZUELA NEWS AND VIEWs. 2012. Blog. Disponível em: daniel-venezuela. blogspot. com.br/2007/08/chavez-and-fidel-castro-as-watermarks. html. Acesso em: 22/09/2012. 